\title{
Electromagnetic Stirring of Molten Core in Continuous Casting of High Carbon Steel*
}

\author{
By Hitoshi IWATA, ,* Katsuhiko YAMADA,** \\ Teruo FUJITA ${ }^{* *}$ and Kyozo HAYASHI**
}

\author{
Synopsis \\ Two-pole rotary field type electromagnetic stirring was applied in the \\ secondary cooling zone to reduce centerline segregation of contimuously cast \\ high carbon steel billets. \\ The results obtained are summarized as follows: \\ (1) A homogeneous macrostructure of equiaxed crystals is obtained by \\ the stirring. \\ (2) The stirring is shown to be more effective at higher casting tempera- \\ tures, by a statistical method which is presented to accurately evaluate the \\ degree of centerline segregation of continuously cast billets. \\ (3) Tensile properties of product, PC Wire, are improved by the \\ stirring.
}

\section{Introduction}

Centerline segregation is one of the serious quality problems inherent to continuously cast billets. Especially, in high carbon steel, positive segregation of carbon along the centerline of billets easily exceeds the eutectoid point and causes the precipitation of cementite networks. This, together with the segregation of other elements or impurities and with the existence of shrinkage cavities and center porosity, reduces the ductility of the materials. It is well known that the intense segregation results in the deterioration of drawability and mechanical properties of steel wires.

These defects occur more frequently in continuously cast billets with smaller cross section. Therefore, the break-down method of bloom with larger section is usually applied to the high grade products. However, to make the most economy of the continuous casting process, it is necessary to improve the quality of continuously cast billets with a smaller section. A lot of research has been done about continuous casting of small sections to determine the influence of casting conditions on the solidification structure or defects of the center part of billets. As for centerline segregation, one of the conclusions is that the segregation is less in a billet with larger homogeneous equiaxed zone.

Electromagnetic stirring (EMS) of the molten core of strands is one of the methods which make columner crystals into equiaxed crystals. Since the patent of Arbing and Rossi, ${ }^{11}$ there has been a lot of research dealing with EMS. Among them, the research by Poppmeier, et al., ${ }^{4)}$ which utilizes the patents by $\mathrm{O}$. Schaaber and S. Junghans, ${ }^{2,3)}$ is worth noticing as they tried for the first time to apply EMS to the real continuous casting process.

They succeeded in improving the cast structure by EMS. Their research is said, however, to have been discontinued because inclusions retained in the billets increased on account of a defect in their apparatus. Research in Russia ${ }^{5)}$ reported that EMS is effective for refining the cast structure but it should be continued until the solidification is completed. They needed equipment with larger output.

The present authors produced a new type apparatus with a simple construction which generates a rotating magnetic field and solves constructional problems. This apparatus was applied to a continuous casting machine for wire products with a small mold size of $115 \mathrm{~mm}$ square. EMS was found to improve the quality of high carbon steel wire. This presentation gives an outline of the results.

\section{Method of Electromagnetic Stirring}

\section{Determination of the Mode of EMS}

The first problem in producing an apparatus for EMS is the stirring flow direction which should be induced. It is not clear which direction of stirring is most effective for preventing defects caused by casting. However, when the shape of the crator is inevitably narrow and deep, stirring around the billet axis is supposed to be adequate for the simplification of the construction and the uniformity of stirring condition. In most of the past research, a rotating field has been adopted. We also followed this precedent.

Figure 1 shows a close relation between the magnetic flux distribution and the number of poles in the rotating field type electromagnetic coil.

Junghans's apparatus, ${ }^{2)}$ Fig. 1 (a) has 3 poles with 3 phases and the flux in the center of the field is weaker than that in the circumferential area. This means that the flux could not act on the molten core in the secondary cooling zone where the solidified shell is already thick.

Figure 1 (b) shows a 4 pole rotating magnetic field
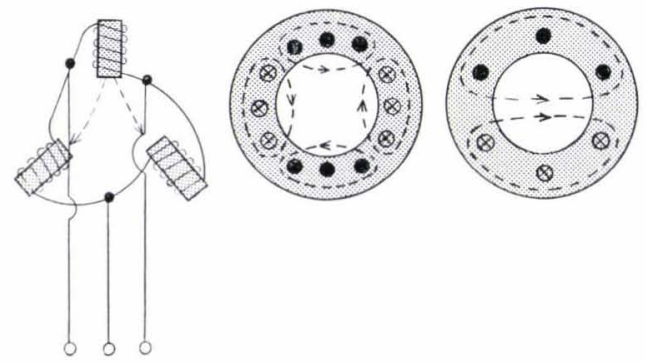

$$
\begin{array}{ccc}
\text { (a) 3-phases } & \text { ( b) 3-phases ( c) 3-phases } \\
\text { 3-poles } & \text { 4-poles } & \text { 2-poles } \\
\text { Fig. 1. Type of rotary magnetic field }
\end{array}
$$

* Originally published in Tetsu-to-Hagané, 61 (1975), 2972, in Japanese. English version received December 5, 1975.

** Sumitomo Electric Industries, Ltd., Miyahigashi, Koya, Itami 664. 
used in Russia. The flux in the center is much weaker than that of 3 pole one. To compensate the weaker flux density, a larger capacity apparatus was needed but still the efficiency was bad. As a result, they insisted that the stirring should be continued until solidification was completed.

Figure 1 (c) shows our apparatus which generates a 2 pole rotating magnetic field. The construction is similar to the stator of a usual 2 pole induction motor. The flux generated by the 2 pole field penetrates along the diameter of the columner cylindrical space inside the stator and provides sufficient flux density in the center of it. A small sized small capacity apparatus of this type is satisfactory.

\section{Choice of the Frequency}

The electromagnetic force acting on the conductor in a rotating field is supposed to be approximately proportional to the conductivity and diameter of the conductor, and the density and the rotation speed of the flux. Most suitable frequency to insure appropriate stirring is not easily chosen since the molten core is surrounded by a solid shell where some extent of induction loss occurs. Moreover, this induction loss increases with the frequency, i.e., the rotation speed of the flux. The commercial frequency was chosen to simplify the apparatus.

\section{Magnetic Flux Density Required}

The flux density was estimated at the center of the magnetic field which could penetrate the solid shell and give a rotating force to the molten core.

The flux density at the center of a 2 pole field is approximately proportional to the ampere turns used but inversely proportional to the distance between the poles, i.e., the inside diameter of the stator. Attempts were made to decrease the distance as short as possible. Because of the limitation arising from the cross sectional dimensions of the billets and the space needed for the construction of the heat- and water-guard, the distance could not be made shorter than $200 \mathrm{~mm}$.

The magnetic shield caused by the guard should be minimized. Therefore, the conductivity and permeability of the guard material should be selected.

Required flux density was evaluated through preliminary experiments using both mercury and molten steel (which are explained in the following paragraph). Stirring of the molten core is not observed at about $50 \mathrm{G}$, but is violent at $300 \mathrm{G}$.

\section{Estimation of the Intensity of Stirring and Determina- tion of Stirring Time}

In examining the macrostructure and the segregation which are supposed to be changed by the stirring, the flow speed of the core should be roughly estimated. This was made with mercury for a velocity of a rotating flow caused by hundreds of $\mathrm{G}$ and a $3600 \mathrm{rpm}$ field.

The depth of vortex induced in mercury placed in a $40 \mathrm{~mm}$ dia. cylinder in the rotating field was measured, and revolutions were calculated in terms of depth by using an equation for forced vortex $:^{6}$ )

$$
\mathcal{N}=60 \cdot\left(\begin{array}{c}
g y \\
2 \pi^{2} x^{2}
\end{array}\right)^{1 / 2}
$$

where, $\mathcal{N}$ : revolutions of a vortex (rpm)

$g$ : acceleration of gravity $(980 \mathrm{~cm} / \mathrm{sec})$

$x$ : radius of a vortex $(\mathrm{cm})$

$y$ : depth of a vortex $(\mathrm{cm})$

A very close linear relation was obtained between the flux density, $B(\mathrm{G})$, and revolutions, $\mathcal{N}$ (rpm), as given at $x=20 \mathrm{~mm}$, by

$$
\mathcal{N}=3.32 B
$$

which gives $1000 \mathrm{rpm}$ at $300 \mathrm{G}$. This revolution corresponds to the circumferential speed of about $2 \mathrm{~m} / \mathrm{sec}$. However, considering conditions in real continuous casting process, such as the square cross section of the molten core, roughness of the solidification front and the viscous drag of molten steel which is larger than that of mercury, the velocity is supposed to be much smaller.

Next, the stirring was considered to be continued until the vortex reaches a steady state at which circumferential speed is at its maximum under applied field. The reason is that the effect of stirring molten core and breaking the tip of crystals was assumed to depend chiefly on the circumferential speed. In the experiment with mercury, the maximum speed was attained in 8 to $10 \mathrm{sec}$.

In order to apply EMS to our continuous casting machine, the size of the magnetic core was fixed at $400 \mathrm{~mm}$ long and the molten core which passes through it was stirred for about $10 \mathrm{sec}$. Since the flux extended slightly beyond upper and lower end of the magnetic core, the molten core was stirred for about $14 \mathrm{sec}$.

\section{Location of the Stirring Apparatus}

There are already some ideas concerning where the apparatus should be located in a continuous casting machine. Poppmeier, et al. ${ }^{4)}$ reported that they hoped to stir in the secondary cooling zone, but could not do it because of the essential deficiencies in their apparatus. When the magnetic coil was located around or just above the mold, the solidified structure was effectively improved, but a vortex was created in the meniscus, scum was gathered in the center of the vortex and carried down into the pool resulting in increased inclusions. Furthermore, a magnetic shield was brought about by the copper mold. If the stirrer is located in the secondary cooling zone, all of these problems are supposed to be solved.

On the other hand, as the appearance of the segregation in a continuous cast billet with a small cross section is thought to be greatly influenced by the formation of the solidification bridge, the stirring must be carried out before the basement of the solidification bridge is formed. The velocity of solidification, temperatur: gradient and the morphology of the solidification front should be considered. It was difficult to estimate them. So, preparatory experiments were carried out on one or two apparatus which 
were attached in a few locations in the secondary cooling zone, and the differences of the tested materials were examined. However, no significant difference was observed. An apparatus was located $2.5 \mathrm{~m}$ below the meniscus, accordingly.

\section{Effects of Electromagnetic Stirring}

\section{Experimental Procedure}

Table 1 shows the outline of the continuous casting machine and the operational conditions. One of the two strands was stirred so as to determine the effect of EMS.

It is well known that under the usual operation, the solidified structure of continuously cast billets with small cross section is determined primarily by casting temperature, while withdrawal speed and the intensity of the spray cooling are of only secondary importance. Therefore, only casting temperature was varied in the experiment.

Table 2 shows the chemical compositions and casting conditions of the tested billets. Liquidus temperatures were calculated by Hirai's equation. ${ }^{8}$

\section{Change of Macrostructure by EMS}

\section{In the Case of High Casting Temperature}

Photograph 1 (a) shows the macrostructure of the longitudinal section of high casting temperature billets, H.C. and H.E. One of the changes induced by

Table 1. Continuous casting machine and electromagnetic stirring equipment

Type of c.c. machine Mitsubishi-Olsson, vertical-bending No. of strands 2

Mold

E.M.S. equipment ;

Power

Structure

Coil

Length of stirring

Stirring time

Setting position

Casting temp.

Casting speed

Spray water for billet, $115 \mathrm{~mm}$ square

30 kVA, $400 \mathrm{G}$

Similar to stator of motor

3 phase, 2 poles, $3600 \mathrm{rpm}$

$560 \mathrm{~mm}$

$14 \mathrm{sec}$

$2.5 \mathrm{~m}$ under meniscus

liquidus $+0 \sim 30^{\circ} \mathrm{C}$

$2.1 \sim 2.4 \mathrm{~m} / \mathrm{min}$

$0.9 l / \mathrm{kg}$ of steel

Table 2. Chemical composition and casting condition of test billets

\begin{tabular}{|c|c|c|c|c|c|c|c|c|}
\hline Sample & C $(\%)$ & $\mathrm{Si}(\%)$ & $\mathrm{Mn}(\%)$ & $\mathrm{P}(\%)$ & $\mathrm{S}(\%)$ & $\begin{array}{l}\text { Super heat. } \\
\Delta T\left({ }^{\circ} \mathrm{C}\right)\end{array}$ & Stirring $(\mathrm{G})$ & $\begin{array}{c}\text { Casting speed } \\
(\mathrm{m} / \mathrm{min})\end{array}$ \\
\hline $\begin{array}{l}\text { H.C. } \\
\text { H.E. }\end{array}$ & 0.75 & 0.28 & 0.58 & 0.014 & 0.017 & 27 & $\begin{array}{r}0 \\
280\end{array}$ & $\begin{array}{l}2.4 \\
2.4\end{array}$ \\
\hline $\begin{array}{l}\text { M.C. } \\
\text { M.E. }\end{array}$ & 0.74 & 0.26 & 0.84 & 0.009 & 0.014 & 10 & $\begin{array}{r}0 \\
280\end{array}$ & $\begin{array}{l}2.4 \\
2.4\end{array}$ \\
\hline $\begin{array}{l}\text { L.C. } \\
\text { L.E. }\end{array}$ & 0.76 & 0.28 & 0.85 & 0.011 & 0.014 & 2 & $\begin{array}{r}0 \\
280\end{array}$ & $\begin{array}{l}2.4 \\
2.4\end{array}$ \\
\hline
\end{tabular}

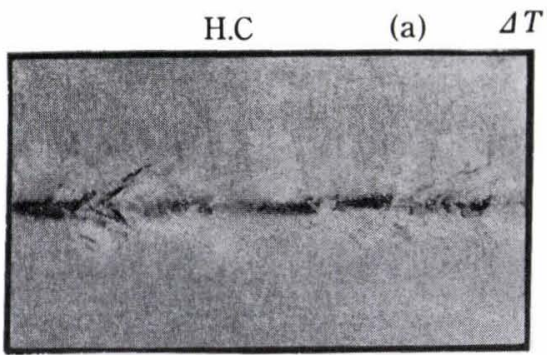

H.E

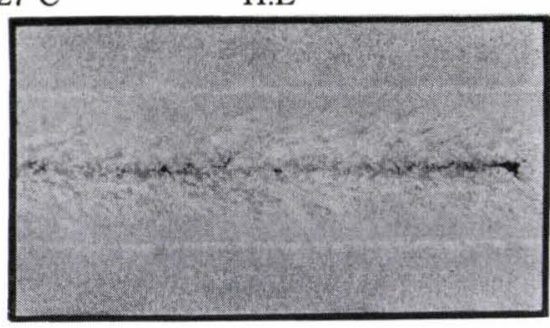

M.C

(b) $\quad \Delta T: 10^{\circ} \mathrm{C}$

M.E
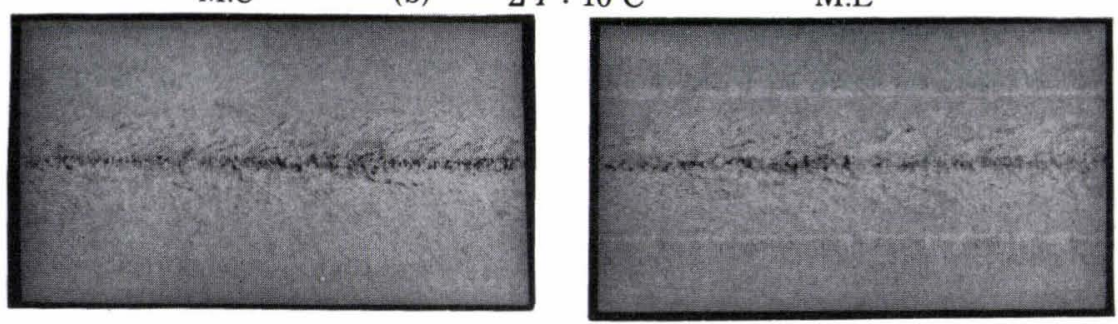

L.C

(c)

$\Delta T: 2^{\circ} \mathrm{C}$

L.E
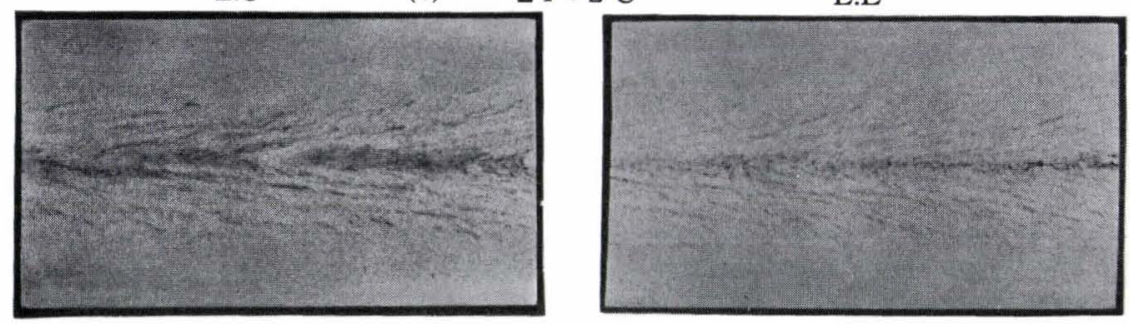

Photo. 1.

Macrostructure in longitudinal section of billets 
EMS is the presence of a white band structure at the place corresponding to the solidification front in the stirring zone. This is called "white band". The macrostructure of the conventional billet, H.C., consists of a chilled zone, columner zone, branched columner and a small quantity of equiaxed crystals, and solidification bridges exist along center axis of the billet. On the other hand, the macrostructure of the stirred billet, H.E., has fine equiaxed crystals inside the white band, and is homogenized along it's longitudinal direction. The shrinkage cavities under the bridges are almost dispersed to be porous structure, but do not completely disappeared.

In the H.C. billet, the intense segregation under a bridge is changed into slight segregation by EMS.

\section{In the Case of Low Gasting Temperature}

Photograph 1 (c) shows the macrostructures of the low casting temperature billets, L.C. and L.E. In this case, the region already solidified before the stirring consists of equiaxed crystals and not of columner crystals. So, the structure inside the white band shows the same homogeneous equiaxed zone as L.C.

\section{White Band}

Photograph 2 shows the macrostructures of the white band in the cross section of the H.E. and L.E. billets. In the macrostructure of high casting temperature billet, the morphology of the dendrite arms inside the white band continues outside of the white band. Moreover, the growing direction of dendrites inclines, at the boundary inside the white band, to the upstream direction of the rotating flow. The boundary is notably white. In a low casting temperature billet, there are no differences in the structures between inside and outside the white band, but there is a slight difference at the boundary.

As mentioned above, the site of the white band which appears after about 14 sec stirring is recognized to correspond chiefly to the part within the liquidsolid zone where interdendritic liquid is washed away by the rotating flow. The width of the white band is supposed to depend on both the width of the liquidsolid zone and the intensity of flow.

\section{Change of Centerline Macro-segregation by Electromag- netic Stirring}

\section{Quantitative Estimation of Centerline Segregation}

The segregation which has a variety of distributions not only in cross sectional but also in the longitudinal direction of billets is hard to describe by a simple onedimensional method. Methods which have been so far employed, for instance, a method ranking billet structure with reference to standard macrostructures ${ }^{7,9)}$ or sampling by a drill from the billet axis, are not satisfactory. More reliable method of estimation was developed in the process of determining the realities of segregation.

At first, the change of solution contents from the surface to central axis of the billet was examined as a method of determining the effect of the stirring on
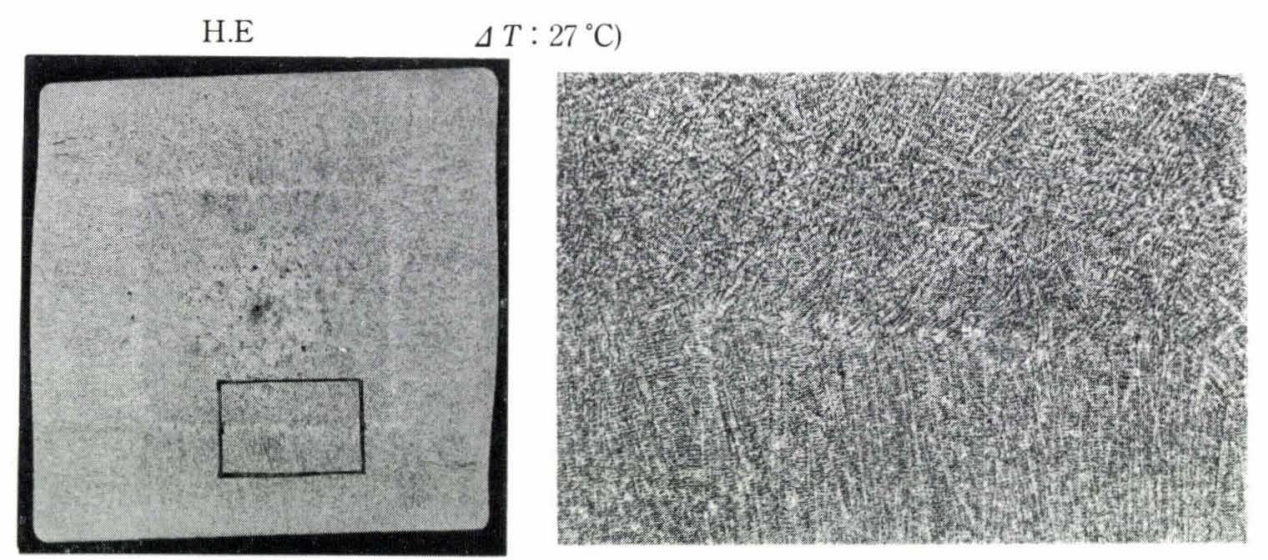

White band

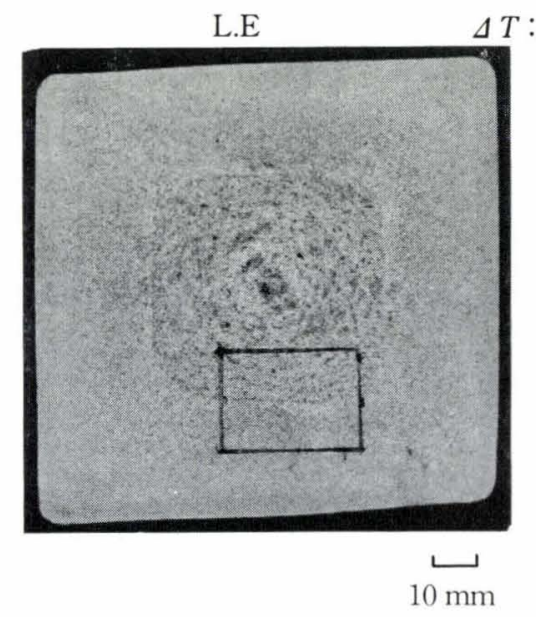
$\left.2^{\circ} \mathrm{C}\right)$

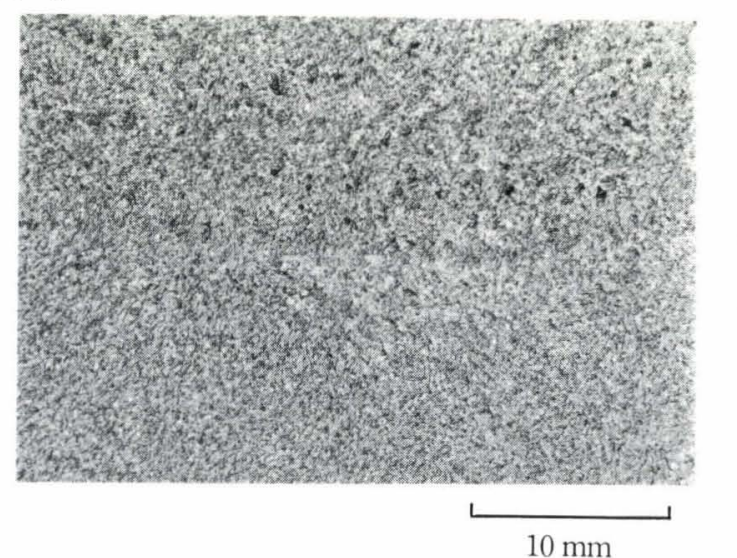

White band

Photo. 2. Macrostructure of white band in transverse sectionof billets 
the centerline segregation. Considering the interval between bridges, billets of $200 \mathrm{~mm}$ long were cut off, and full length samples of $2.5 \mathrm{~mm}$ wide were shaved off for chemical analysis by a shaper from the surface to the center at $1 \mathrm{~mm}$ thickness intervals.

Figure 2 shows cross-directional segregation obtained by this method. The figure includes segrega-

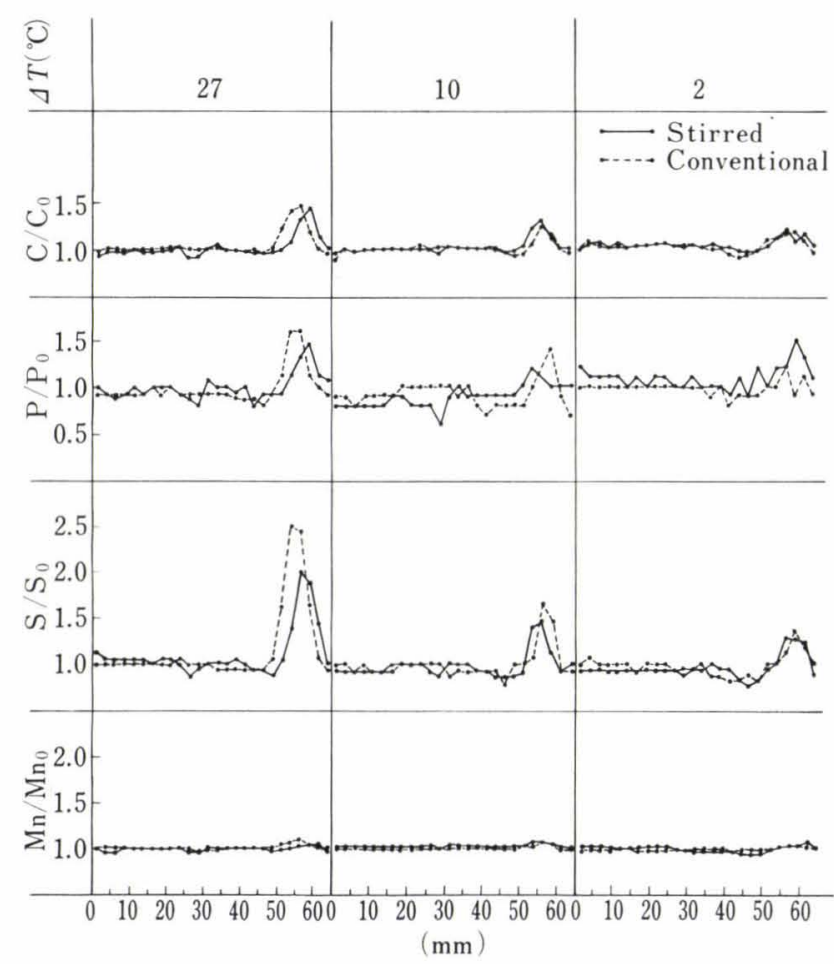

Fig. 2. Change of C, P, S and Mn from the surface to the center of billet tion of $\mathrm{C}, \mathrm{P}, \mathrm{S}$ and $\mathrm{Mn}$ in six samples.

In the figure, one sees the followings:

(1) The centerline segregation is located in the center part and has a diameter of 10 to $15 \mathrm{~mm}$. The diameter of the drill by which sampling is made significantly influences the results, accordingly.

(2) Centerline segregation of C, P, S and $\mathrm{Mn}$ is surrounded by counter-balancing weak negative segregation.

(3) Centerline segregation develops with increasing casting temperature.

(4) Centerline segregation is more marked for $\mathrm{S}, \mathrm{P}$ and $\mathrm{C}$ in this order than for $\mathrm{Mn}$.

(5) Effects of stirring on centerline segregation are not marked in this figure.

(6) The white band exhibits negative segregation.

If the width of the white band is $3 \mathrm{~mm}$ and the segregation ratio of a solute at the white band is 0.9 , the segregation ratio of the solute inside the white band is increased by 0.02 .

Figure 3 shows the segregation ratio of $\mathrm{P}, \mathrm{S}$ or $\mathrm{Mn}$ against that of $\mathrm{C}$. Using these functionalities, the segregation ratio of each element can be estimated by analyzing only the $\mathrm{C}$ content.

The extent of the centerline segregation can not be judged only by the data in Fig. 2, since each plot indicates only the average value in the longitudinal direction in a $200 \mathrm{~mm}$ long billet. Therefore, the change of $\mathrm{C}$ content along the billet axis should be examined. For this purpose, samples each $5 \mathrm{~mm}$ long, were taken with a $5 \mathrm{~mm}$ dia. drill along the billet axis at $5 \mathrm{~mm}$ intervals, i.e., 40 samples were taken from a $200 \mathrm{~mm}$ long billet.

Photograph 3 shows change of centerline segrega-
H.C. $\left(\Delta T: 27^{\circ} \mathrm{C}\right)$

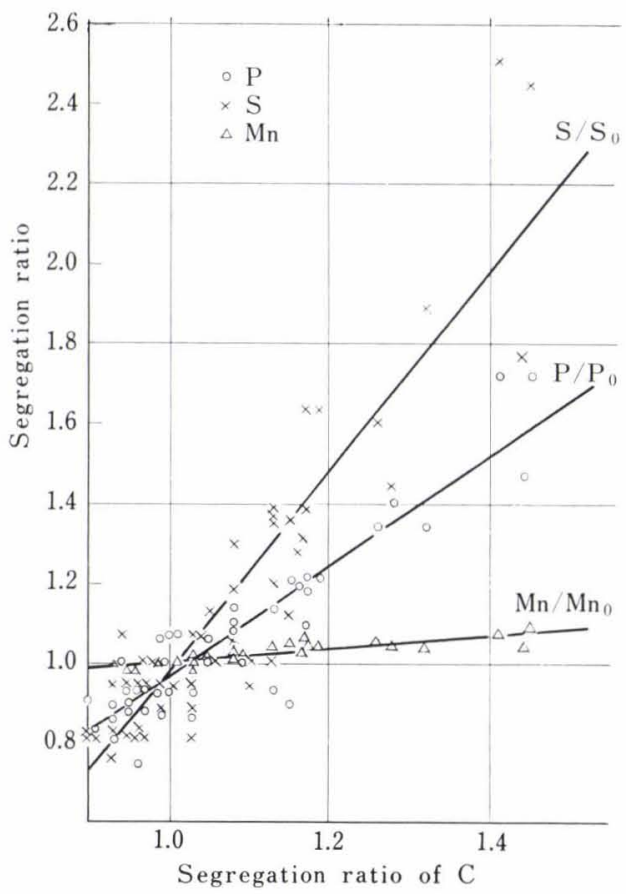

Fig. 3. Relation between $\mathrm{C} / \mathrm{C}_{0}$ and $\mathrm{P} / \mathrm{P}_{0}$, $\mathrm{S} / \mathrm{S}_{0}, \mathrm{Mn} / \mathrm{Mn}_{0}$
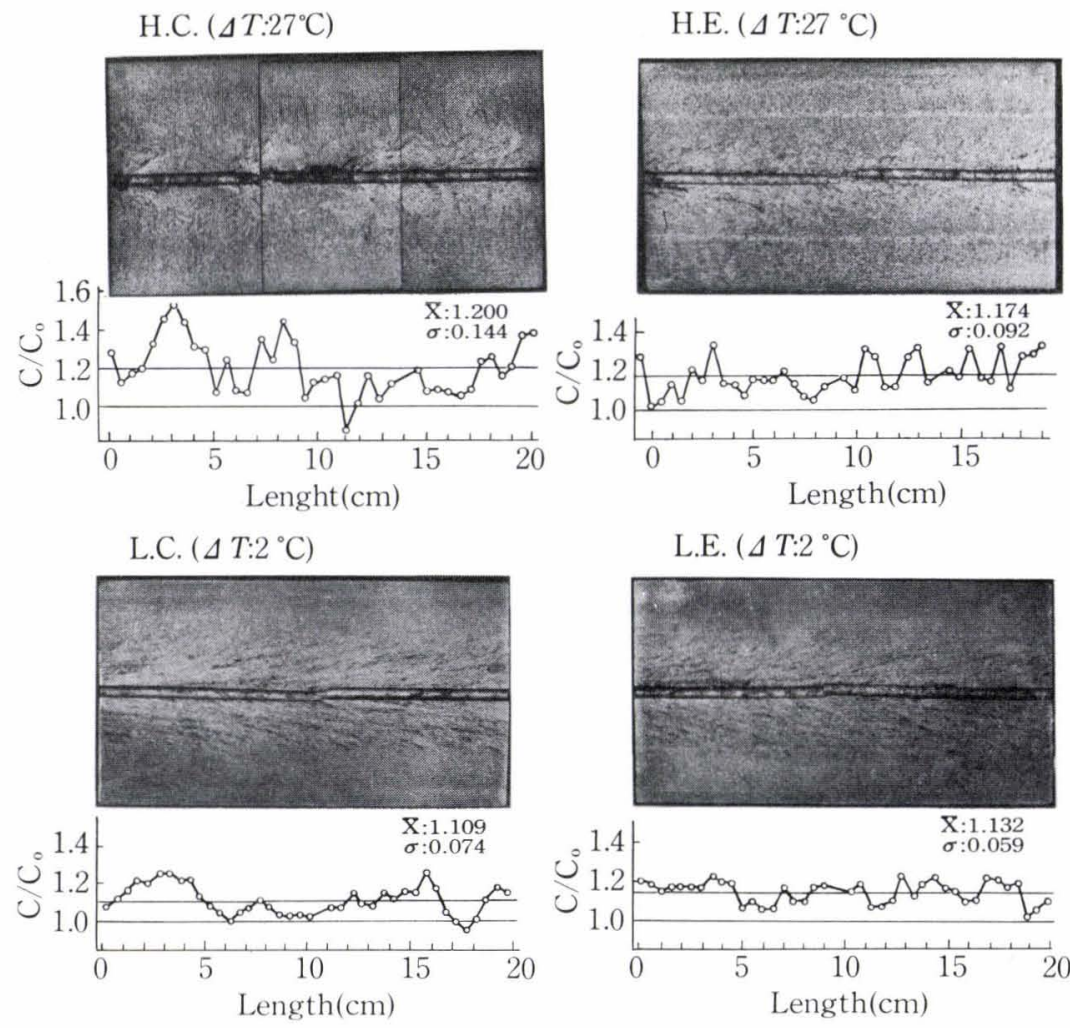

L.E. $\left(\Delta T: 2^{\circ} \mathrm{C}\right)$
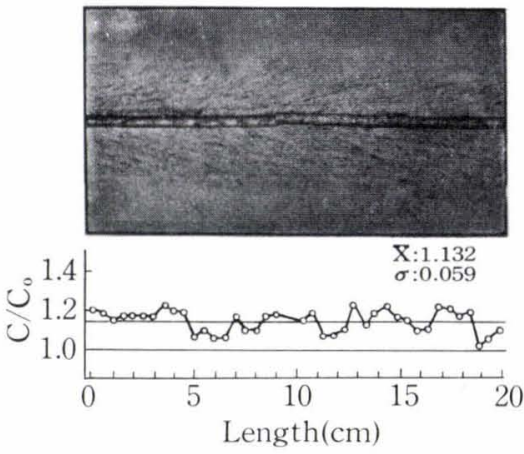

Photo. 3. Change of $\mathrm{C}$ segregation along centerline of billets 
tion ratio of $\mathrm{C}$ in longitudinal direction in comparison with the corresponding macrostructure. In a high casting temperature billet H.C., the segregation ratio as estimated from the macrostructure fluctuates intensely at the upper and lower portion of the bridge. In the stirred billet H.E., the periodic fluctuation of the segregation ratio caused by the bridges disappeared, but still the fluctuation cannot be neglected. In a low casting temperature billet, L.C., despite the homogenity of it's macrostructure, the segregation ratio shows the same periodic fluctuation as that of H.C., but the average value is small. In low casting temperature billets, too, the periodic fluctuation disappeared with stirring.

From these observations, two points must be made clear to estimate the degree of the centerline segregation ratio.

The first is that length of billet samples must cover at least one cycle of the fluctuation of the centerline segregation ratio which corresponds to the intervals between bridges. Therefore, billet samples of tens $\mathrm{cm}$ are needed.

The second is that segregation which causes trouble in subsequent process is local, unusual and intense one. Therefore, the mean value of the centerline segregation ratio is important but the value of segregation ratio and the frequency of such local segregation are more important.

Figure 4 shows the data in Photo. 3 rearranged into histograms. The influence of casting temperature and stirring on the centerline segregation ratio is more precisely evaluated in Fig. 4 than in Fig. 2 for the shaper method:

(1) In the conventional billet, the mean value and the standard deviation of centerline segregation ratio increase with casting temperature, hence the frequency of local, intense segregation increases.

(2) In the stirred billet, though there is the same inclination as mentioned in (1), the standard deviation of the centerline segregation ratio is decreased less than that of the conventional billet. The frequency of the local, intense segregation is also reduced.

Figure 5 shows the relation between the mean value $(\bar{X})$ and the standard deviation $(\sigma)$ of the centerline segregation ratio analyzed along the axis of the billets. In the conventional billets, there is a correlation between the two, but in the stirred billets, $\sigma$ is reduced and at the same time, the correlation is indistinct. As a result, in conventional billets, the degree of segregation can be compared with each other

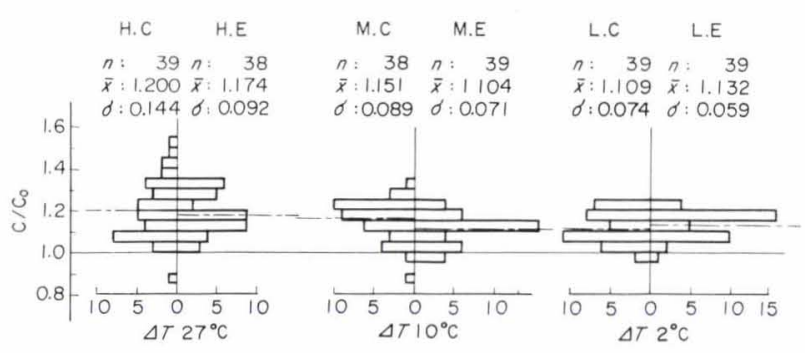

Fig. 4. Histogram of center segregation ratio of $\mathrm{C}$ for various casting conditions only by the mean value, but in the stirred billets, the standard deviation must be calculated separately. Therefore, the general evaluation of the centerline segregation can be done by both the mean value and the standard deviation of the centerline segregation analyzed along the billet axis.

2. The Influence of Casting Temperature and Electromagnetic Stirring on the Centerline Segregation

Billet samples of about $600 \mathrm{~mm}$ long were cut off from the billets cast under various conditions, and samples for $\mathrm{C}$ analysis were gathered by drilling each $25 \mathrm{~mm}$ deep along the billet axis.

The mean value, $\overline{\mathrm{C}}$, and the standard deviation, $\sigma_{c}$, were calculated and $\left(\mathrm{C} / \mathrm{C}_{0}\right)_{\max }=\left(\overline{\mathrm{C}}+3 \sigma_{c}\right) / \mathrm{C}_{0}$ was defined as the maximum segregation ratio.

Figure 6 shows the influence of casting temperature and stirring on the maximum segregation ratio.

It should be noted, in Fig. 4, that the values of the centerline segregation ratio of $\mathrm{C}$ give normal distribution, the frequency of the local segregation which is more intense than $\left(\mathrm{C} / \mathrm{C}_{0}\right)_{\max }$ defined before is supposed to be $0.14 \%$ by a statistical calculation.

We think that this estimation method is more accurate and practical than the usual methods, e.g., ranking a billet structure with reference to standard macrostructures or one point analysis method by shaper or drill-sampling.

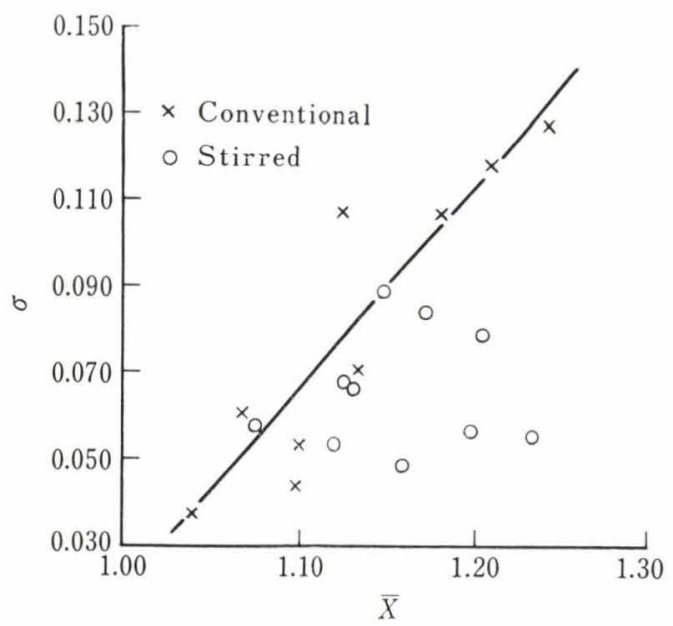

Fig. 5. Relation between standard deviation $(\sigma)$ and mean value $(\bar{X})$ of center segregation ratio of $\mathrm{C}$

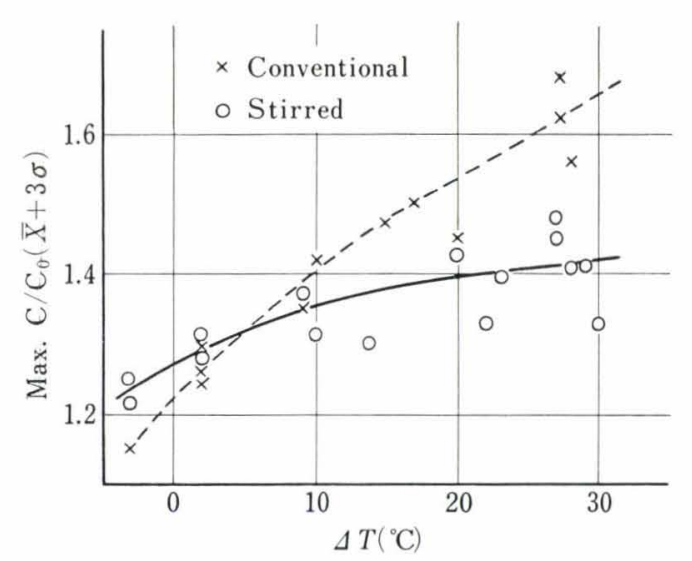

Fig. 6. Effect of casting conditions on maximum segregation ratio $(\bar{X}+3 \sigma)$ 
In Fig. 6, $\left(\mathrm{C} / \mathrm{C}_{0}\right)_{\max }$ clearly increases with casting temperature irrespective of stirring, and the effect of stirring becomes apparent at higher casting temperature.

\section{Rods}

Photograph 4 (a) shows the macrostructure of rods which have intense segregation. The center part of the rods looks darkish. In the microstructure of the center part, cementite network is usually observed, austenite grains are smaller than the surrounding, and sometimes fine groups of sulphides are observed. In the stirred rods in Photo. 4 (b), white bands remain and the darkish centerline segregation marks disappear or are lightened and change into many stripes of light segregation. It is supposed that a part of the segregation which is concentrated at the center part is dispersed by the stirring.

A light segregation disappears during the following patenting process, but an intense segregation causes the cementite network to appear again and decreases the drawability. Segregation is evaluated to a certain degree by the cross sectional macrostructure of rods. It is confirmed that the segregation is decreased by the stirring.

Table 3 shows a comparison during a tensile test of the reduction of area of the rods subjected to lead patenting. The tested samples are $10.0 \mathrm{~mm}$ dia. rods obtained from many melts which were cast into one stirred strand and the other unstirred strand. There is no difference in the tensile strength between the two but the reduction of area is improved slightly by stirring.

\section{Wires}

Defects such as segregation or shrinkage cavity along the axis of rods cause many troubles during cold drawing and adversely affect the quality of the final products. An examination of high carbon steel wire in this regard is shown in the following.

If the intensity of the defects is comparatively small the tensile strength of the wire is not influenced at all, but the elongation and the reduction of area are decreased and the wire does not give the normal fracture surface of cup and corn shape. For samples with intense defects, the fractured surface shows typical cuppy shape, resulting in small value of reduction of area. With such defects, toughness and tensile strength are deteriorated. More intense defects cause the breaking of wires during the drawing or stranding process.

Table 4 shows the effect of the stirring on the frequency of cuppy-like fracture (Photo. 5) appeared during tensile test of PC wires produced by the following process.

C.C. (113 mm square) $\rightarrow$ rolling (12.3 mm dia.) $\rightarrow$ patenting $\rightarrow$ drawing $(7.0 \mathrm{~mm}$ dia.)

(a)
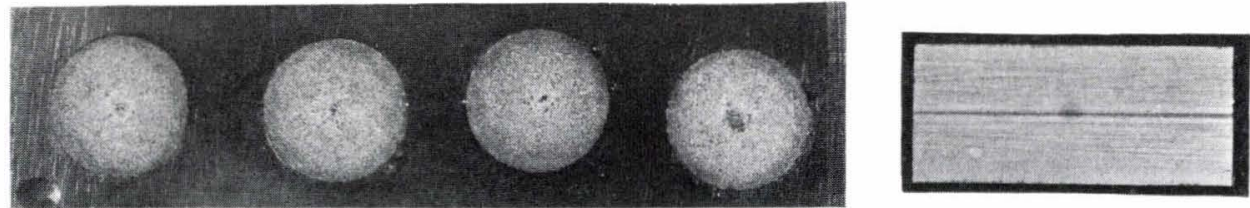

(b)
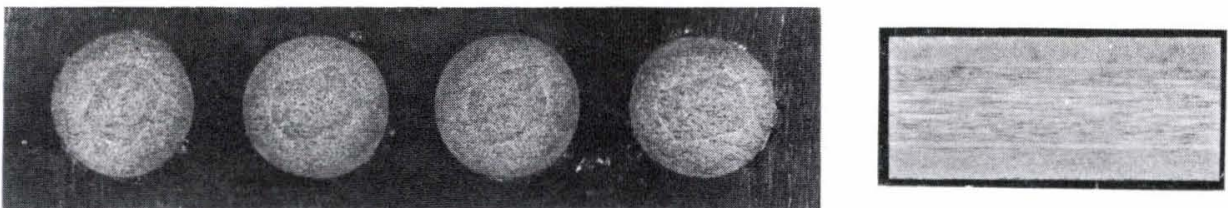

Photo. 4. Macrostructure of transverse and longitudinal section of $10 \mathrm{~mm}$ dia. rods

Table 3. Comparison of reduction in area of the rods subjected to lead-patenting

\begin{tabular}{|c|c|c|c|c|c|c|c|}
\hline $\begin{array}{c}\text { Charge } \\
\text { No. }\end{array}$ & $\begin{array}{c}\mathrm{C} \\
(\%)\end{array}$ & $\begin{array}{l}\mathrm{Mn} \\
(\%)\end{array}$ & $\begin{array}{l}\text { Dia. of } \\
\text { rods } \\
(\mathrm{mm})\end{array}$ & $\begin{array}{l}\text { Stir- } \\
\text { ring }\end{array}$ & $\begin{array}{l}\text { No. of } \\
\text { samples }\end{array}$ & $\begin{array}{l}\text { R.A. } \\
(\%)\end{array}$ & $\begin{array}{l}\text { Diff. } \\
(\%)\end{array}$ \\
\hline 1 & 0.77 & 0.88 & $\begin{array}{l}10 \\
,\end{array}$ & $\begin{array}{l}\text { with } \\
\text { no }\end{array}$ & $\begin{array}{l}5 \\
"\end{array}$ & $\begin{array}{l}23.1 \\
20.1\end{array}$ & +3.0 \\
\hline 2 & 0.75 & 0.83 & ," & $\begin{array}{l}\text { with } \\
\text { no }\end{array}$ & ” & $\begin{array}{l}26.9 \\
24.6\end{array}$ & +2.3 \\
\hline 3 & 0.76 & 0.85 & ” & $\begin{array}{l}\text { with } \\
\text { no }\end{array}$ & ", & $\begin{array}{l}25.2 \\
24.1\end{array}$ & +1.1 \\
\hline 4 & 0.78 & 0.86 & $\begin{array}{l}" \\
,\end{array}$ & $\begin{array}{l}\text { with } \\
\text { no }\end{array}$ & ”, & $\begin{array}{l}28.1 \\
25.3\end{array}$ & +2.8 \\
\hline 5 & 0.77 & 0.86 & " & $\begin{array}{l}\text { with } \\
\text { no }\end{array}$ & ”, & $\begin{array}{l}24.8 \\
22.5\end{array}$ & +2.3 \\
\hline
\end{tabular}

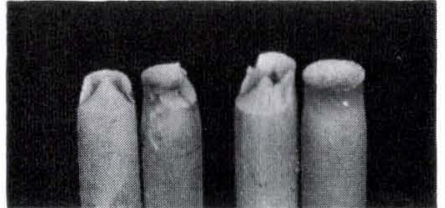

Photo. 5. Cuppy-like fracture

Table 4. Cuppy-like fracture on tensile test of PC wire

\begin{tabular}{l|c|c|c|}
\multicolumn{1}{c|}{ Billet } & $\begin{array}{c}\text { No. of } \\
\text { charge }\end{array}$ & $\begin{array}{c}\text { Magnetic } \\
\text { flux }(\mathrm{G})\end{array}$ & $\begin{array}{c}\text { Ratio of defect } \\
(\%)\end{array}$ \\
\hline Conventional & 52 & 0,0 & $62 / 2995=2.1$ \\
Stirring one strand & 30 & 0,240 & $29 / 1785=1.6$ \\
" & 27 & 0,290 & $20 / 1660=1.2$ \\
Stirring both strands & 16 & 290,290 & \multicolumn{1}{c}{$6 / 791=0.76$}
\end{tabular}


It is apparent in Table 4 that electromagnetic stirring is effective in improving the tensile characteristics of steel wires.

\section{Conclusions}

In order to reduce the intensity of the centerline segregation of continuously cast high carbon steel billets, the molten core of the strands was stirred by a 2 poles type rotating electromagnetic field at the secondary cooling zone. The evaluations are the followings.

(1) A homogeneous macrostructure of equiaxed crystals are obtained by the stirring.

(2) A method is proposed to quantitatively evaluate the centerline segregation, by utilizing many samples gathered along the billet axis and the mean value and the standard deviation of the chemistry of the samples.

(3) By using this method, the electromagnetic stirring is shown to be more effective for the segregation when the casting temperature is higher.

(4) The white band produced by the stirring remains in the final products, but does not cause any quality problem.
(5) The frequency of appearance of cuppy-like fracture of steel wires which is greatly influenced by the centerline segregation decreases drastically with stirring.

\section{REFERENCES}

1) Japanese Patent Application Publication, No. 2768/1958.

2) D.P.B. 902434.

3) D.P.B. 911425.

4) W. Poppmeier, B. Tarmann and O. Schaaber: J. Metals, 18 (1966), 10, 1109.

5) Непрерывная разливка стали, Госдарственное Научно Техническое Издательство, (1961).

6) Chuzogijutsu Koza 10, Tokushu Chuzo Ho, Nikkan Kogyo, (1968), 237.

7) H. Mori, N. Tanaka, N. Sato and M. Hirai: Tetsu-toHagané, 57 (1971), 263.

8) M. Hirai, K. Kanamaru and H. Mori: Tetsu-to-Hagané, 52 (1969), S85.

9) S. Takaishi, T. Komai, K. Noro and Y. Akita: Tetsu-toHagané, 60 (1974), 915.

10) А.Д. Акименко, А.А. Сквордов, Л.П. Орлов and Л.В. Шенделов: Непрерывное Литье во Вращающемся Магнитном Поле, Издательство Металлургия Москва (1971), 147. 